\title{
TRATAMIENTO INFORMATIVO DE LAS ESPOSAS Y NOVIAS (WAGS) DE LOS DEPORTISTAS EN LA PRENSA DIGITAL DEPORTIVA ESPAÑOLA
}

\author{
Informative treatment of sportsmen's wives and \\ girlfriends (WAGs) in Spanish sport digital press
}

Ana M. Muñoz-Muñoz y Juana Salido-Fernández

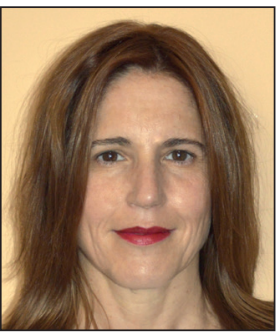

Ana M. Muñoz-Muñoz es profesora titular del Departamento de Información y Comunicación de la Universidad de Granada. Miembro del grupo de investigación EC3, y del Instituto Universitario de Investigación de Estudios de las Mujeres y de Género de la misma universidad, del que actualmente es directora. Su investigación se centra en la documentación desde una perspectiva de género. Destaca: Mujeres y ciencia: producción científica desde una perspectiva de género; El cuerpo y sus significados: la imagen de la mujer prensa, fotografía y publicidad; Fuentes de información para los estudios de las mujeres y de género.

https://orcid.org/0000-0003-4575-698X

anamaria@ugr.es

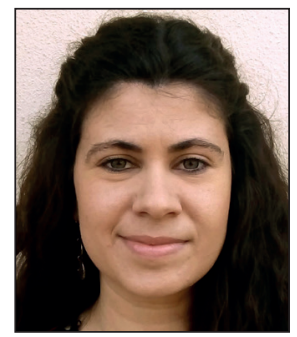

Juana Salido-Fernández es licenciada en periodismo por la Universidad de Sevilla y Master de doble titulación en Historia de Europa, El Mundo Mediterráneo y su Difusión Atlántica por la Universidad Pablo de Olavide. Actualmente está cursando el Programa de doctorado Estudios de las Mujeres, Discursos y Prácticas de Género de la Universidad de Granada. Sus líneas de investigación están relacionadas con estudios de género, medios digitales y periodismo deportivo. Ha trabajado como coordinadora de Planes de Igualdad y actualmente es periodista en gabinete de comunicación institucional.

https://orcid.org/0000-0001-9107-300X

juanasalido@correo.ugr.es

Universidad de Granada Instituto Universitario de Investigación de Estudios de las Mujeres y de Género Rector López Argueta, s/n. 18071 Granada, España

\section{Resumen}

Se estudia el tratamiento informativo de los medios digitales deportivos sobre las esposas y novias de deportistas (WAGs, wives and girlfriends of sportsmen) a partir de una población de 418 noticias publicadas en los cuatro diarios digitales deportivos de mayor número de lectores: Marca, As, Mundo deportivo y Sport. La metodología aplicada ha sido el análisis de contenido, a partir del cual se ha creado una ficha de análisis con diez campos. Se analiza la presencia del fenómeno entre 2000 y 2015, las secciones, deporte, tipo y extensión de las noticias, su autoría, titulares, temática principal, informaciones negativas, y el rol desempeñado por las mujeres protagonistas. Los resultados muestran un notable incremento de las noticias sobre WAGs en los últimos años, especialmente en noticias breves destinadas a entretenimiento, con abundante presencia de imágenes, y asociadas a roles de belleza, maternidad y dependencia del varón.

\section{Palabras clave}

Prensa digital; Prensa deportiva; Diarios; Deportes; Mujeres; Estereotipos de género; Imagen femenina; Análisis de contenido; WAGs; As; Marca; Mundo deportivo; Sport.

\begin{abstract}
This paper studies the coverage of WAGs (wives and girlfriends of sportsmen) in online sports-media by analyzing 418 articles published in four major online sports' newspapers in Spain: Marca, As, Mundo deportivo, and Sport. A content analysis was used to create a card of analysis with ten fields. Thus, the paper analyzes the evolution of this phenomenon between 2000 and 2015; the sections, sport, type, and extension of such news; authorship, headlines, main theme, and information linked to negative facts about them; and the role played by women. Results show a significant increase in news coverage about WAGs in all newspapers. The coverage is mainly short news stories with abundant images; located in entertainment sections; associated with beauty, motherhood, male dependence, and subordination.
\end{abstract}




\section{Keywords}

Digital press; Sport press; Newspapers; Sports; Women; Gender stereotypes; Female image; Content analysis; Athletes; Pro-athletes; Sportmen; Wives and girlfriends; WAGs; As; Marca; Mundo deportivo; Sport.

Muñoz-Muñoz, Ana M.; Salido-Fernández, Juana (2018). "Tratamiento informativo de las esposas y novias (WAGs) de los deportistas en la prensa digital deportiva española". El profesional de la información, v. 27, n. 2, pp. 331-340.

https://doi.org/10.3145/epi.2018.mar.11

\section{Introducción y estado de la cuestión}

Los medios de comunicación contribuyen a la formación de la opinión pública (Lippmann, 2003), son una fuente imprescindible de información para los ciudadanos e influyen en los discursos interiorizados socialmente. Por ello numerosos estudios han analizado el desequilibrio en noticias referidas a los géneros masculino y femenino (Duncan; Messner; WiIliams, 1991; Pearson; Turner; Mancillas, 1993; Messner; Cooky, 2010). La información deportiva es una de las que mayor demanda tiene en la sociedad e influye en:

"la labor de promoción deportiva entre la población de cualquier edad, sexo y condición" (Sainz-de-Baranda-Andújar, 2014a, p. 91).

A pesar de tal responsabilidad, es:

"una de las manifestaciones periodísticas que de forma más clara transmite estereotipos sexistas" (Rojas-Torrijos, 2010, p. 127),

al contar la realidad de forma androcéntrica y tratar a la mujer en desigualdad con respecto al varón. Sobre la trivialización de las deportistas destacan los trabajos de Hargreaves (1994) o Roth y Basow (2004).

La incidencia de las noticias deportivas se traduce en una ausencia de referentes deportivos femeninos (García-Altadill; De-Moragas; Gómez-Benosa, 1994; Frideres; Palao-Andrés, 2006). Expresado en cifras:

"la mujer es sujeto noticioso únicamente en el 5,11\% de los casos -unas veces sola $(2,18 \%)$ y otras acompañada por al menos un protagonista masculino (2,93\%)-, mientras que el hombre lo es en el 92,24\%" (Sainz-de-Baranda-Andújar, 2014b, p. 1225).

Estos contenidos son trivializados, al representar escasamente a las deportistas e incrementar los estereotipos hacia ellas (Fink; Kensicki, 2002). Para García-Meseguer (2002) son invisibilizadas y referidas mediante un lenguaje sexista y con roles estereotipados como "esposas, novias o madres de atletas masculinos famosos" (Messner; Cooky, 2010, p. 5). De esta manera, los ciudadanos se ven determinados por las representaciones arqueotipadas de género que reciben.

Numerosos autores han teorizado sobre los cambios producidos por los medios online. Según Scolari (2008, pp. 5556) suponen una transformación basada en la convergencia, el desplazamiento hacia formas mucho más "reticulares e interactivas" con las audiencias, y son capaces de generar una retroalimentación continua y nuevos hábitos de consumo mediático que dejan de ser familiares para acercarse a la "pervasividad" y la segmentación. Estas nuevas formas de consumo influyen en los procesos de interpretación de las audiencias. A pesar de estos cambios la representación del género en las nuevas tecnologías puede fomentar la desigualdad (Ayala-Castro; Fernández-Soriano; Fernández-de-la-Torre, 2001, p. 184) debido a que suelen presentar a las mujeres con "un papel pasivo, consumista, sometido, o incluso, como mero objeto sexual". Hacia esta idea también avanzan Martínez-Oña y Muñoz-Muñoz (2015) o Franquet, Luzón y Ramajo (2006, p. 12) para quienes

"la representación del género femenino en los medios de comunicación online sigue las pautas de representación de los medios tradicionales, renunciando a la capacidad de innovación o diferenciación".

Los diarios españoles e internacionales utilizan el término WAGs (wives and girlfriends of sportsmen) para referirse a las esposas y novias de los deportistas profesionales

El término WAGs es un acrónimo formado a partir de wives and girlfriends of sportsmen, que se utiliza en los medios para referirse a las esposas y novias de los deportistas profesionales. Este acrónimo tiene otros significados en sus dos primeras acepciones según el diccionario Collins:

"1. to move or cause to move rapidly and repeatedly from side to side or up and down.

2. to move (the tongue) or (of the tongue) to be moved rapidly in talking, esp in idle gossip".

“1. Mover o hacer que se muevan rápidamente y en repetidas ocasiones de lado a lado o de arriba abajo.

2. Mover (referido a la lengua) rápidamente para hablar, especialmente sobre chismes".

Diccionarios como WordReference.com recogen un significado similar, referido a menear, mover, meneo o agitar, lo que incorpora una serie de connotaciones sobre estas mujeres al ser mencionadas.

Aunque el origen del acrónimo no está claro (Harditya, 2013; Bullen, 2014), su máxima difusión se produjo en el Mundial de Alemania de 2006. Para Harditya, los diarios británicos utilizaban esta palabra para mostrar resentimiento hacia las novias y esposas de los deportistas que, según ellos, interferían negativamente en la concentración del equipo nacional de Inglaterra. Después pasó a designar en la prensa deportiva a todas las esposas y novias de deportistas profesionales, especialmente a aquellas vinculadas a 
la moda y que responden a los cánones de belleza actuales.

En su estudio sobre jugadores de fútbol, Morris (1981, p. 181) considera que estos "guerreros" y "cazadores" buscan un ideal de mujeres femeninas, hermosas, alegres y que no resulten problemáticas, ya que el deportista tiene suficientes preocupaciones en el campo y busca la tranquilidad familiar. Ellas deben proporcionar matrimonios duraderos y felices y una vida satisfactoria basada en la maternidad y crianza de los hijos, algo que reflejan los medios de comunicación de masas. Estas mujeres (Gmelch; San-Antonio, 2001; Clayton; Harris, 2004; Harris, 2005; Forsyth; Thompson, 2007) representan las expectativas mayoritarias de la idea tradicional de feminidad, con roles de dependencia, subordinación y adulación excesiva de los deportistas. Facilitan la carrera profesional de sus esposos y desvían las tensiones provenientes del fútbol, sirviendo de afirmación de la virilidad arquetípica y heterosexualidad obligatoria del varón, mientras "disfrutan del gran éxito profesional de sus parejas" (Vaczi, 2014, p. 300). Vaczi les asocia dos perfiles:

- uno como mujeres fatales, al ser presentadas en los medios deportivos como peligrosas y una amenaza capaz de desestabilizar con su sexualidad a los deportistas y su rendimiento profesional como élite masculina;

- como objeto sexual que "alimenta las fantasías eróticas de los aficionados [...] y convierte el paisaje del deporte masculino en un espacio sexy" (Caudwell; Browne, 2011, p. 117).

Distintos autores encuentran gran desigualdad en deportes como el fútbol (Connell, 1987; Koivula, 1999; Bishop; 2003; Clayton; Humberstone, 2006; Rubinstein; Lansisky, 2013), siendo designado como una institución creada por y para los hombres. El fútbol ha servido para reforzar la ideología de superioridad mediante la proyección de ideales hegemónicos. El fútbol, como el deporte más popular del mundo, facilita y trasmite la cultura hegemónica de masculinidad y feminidad (Rubin, 2009), siendo un espacio reproductor de desigualdades y hegemonía del varón. La masculinidad hegemónica propia de los deportes tiene unas características culturalmente idealizadas, basadas en la agresividad, la imagen del cuerpo masculino como privilegiado, competitividad y mantenimiento de un patriarcado familiar de dominación de la esposa y de los hijos (Trujillo, 1991). Los medios deportivos refuerzan estos privilegios masculinos, glorifican la labor de los atletas varones y acentúan la división sexual del trabajo y las diferencias de género (Burstyn, 1999).

Estos ideales legitiman el dominante rol masculino, que resulta complementado y reforzado por patrones autorizados de feminidad (belleza, pasividad y apoyo). Las mujeres que encarnan estas características son cómplices de los patrones de hegemonía presentes en el fútbol (Vaczi, 2014).

La marcada sexualización que reproduce la cultura general, incluyendo los medios de masas, supone un impacto nocivo para niñas y mujeres jóvenes, al influir en sus aspiraciones, logros (Coy, 2009), pero también en su definición de feminidad, belleza y en sus relaciones e interacciones sexuales. Según analiza Coy, éstas relegan el esfuerzo y logro académico para convertirse en esposas de futbolistas y modelos. Allen y
Mendick (2013) retoman esta idea del éxito sin talento mediante el uso del cuerpo en lugar de la mente. Para las WAGs su condición de celebridad se define por asociación a alguien famoso por su talento, no por ellas mismas, siendo percibidas como mujeres que usan su sexualidad como forma de vida.

Para evidenciar si existen tales desequilibrios, el objetivo principal de esta investigación es analizar el tratamiento mediático sobre WAGs en los principales diarios digitales deportivos españoles. Como objetivos específicos se analizará la presencia del término en la prensa digital desde su aparición hasta finales de 2015, la distribución de las noticias por sección, deporte, extensión, tipo de noticia, autoría, así como los titulares, tema principal, uso de términos negativos y roles que se asignan a estas mujeres.

Atendiendo a los anteriores objetivos, en este artículo se plantean las siguientes hipótesis de trabajo:

- Existe un tratamiento desigual entre hombres y mujeres en la prensa deportiva.

- El término WAGs se viene utilizando de forma creciente en este tipo de prensa.

- La autoría de noticias sobre WAGs recae principalmente sobre hombres.

- Los roles tradicionales de género se ven reforzados mediante las noticias sobre WAGs

- Las noticias sobre WAGs revelan una visión banalizada de las mujeres y un tratamiento que las retrata como estereotipos de la mujer dependiente y subordinada.

\section{Metodología}

La población está constituida por todas las noticias sobre WAGs publicadas en los cuatro periódicos deportivos digitales de mayor número de lectores en España (AIMC, 2015):

- Marca.com (5.142.000);

- As.com (2.575.000);

- Elmundodeportivo.com (1.368.000);

- Sport.es (1.206.000),

debido a su presencia y repercusión en todo el país, especialmente entre el público masculino, lector habitual de tales contenidos. Dado que las informaciones sobre WAGs son incompletas en dos de estos periódicos, porque el grueso de las mismas se concentra en los blogs asociados a ellos, se ha ampliado el análisis a éstos para incluirlas. Así Marca. buzz en Marca y El balón rosa en Sport son analizados de igual forma al estar insertos en tales diarios como contenido habitual, con una estructura y diseño de noticias similares. Han sido recogidas todas las noticias que contenían en su titular o cuerpo de texto las palabras WAG y WAGs, desde el inicio de cada una de sus ediciones digitales (Marca 1995, As 2000, Mundo deportivo 1995 y Sport 2000) hasta diciembre de 2015

Con la metodología aplicada al análisis de contenido (Krippendorff, 1990; Bardin, 2002), a partir de la búsqueda de los términos WAG y WAGs en las casillas de búsqueda de las plataformas digitales de los diarios, se han revisado las noticias una a una (debido a que no ofrecen la opción de búsqueda avanzada) y eliminado las repetidas, siendo seleccionadas en total 418 noticias vinculadas a este perfil de los cuatro diarios digitales. 
Se ha realizado un análisis estadístico descriptivo para recopilar, tratar, presentar y analizar los datos estableciendo frecuencias y porcentajes con el software Microsoft Office Excel 2007.

Toda la información ha sido volcada en una ficha de análisis, teniendo en cuenta la "guía de análisis de prensa deportiva" de Sainz-De-Baranda-Andújar (2013, pp. 115-117). La ficha se compone de diez campos:

- diario

- fecha

- sección

- deporte

- extensión y tipo de noticia (fotonoticia, videonoticia, fotogalería y noticia con o sin imágenes)

- autoría

- titulares

- tema principal (relación sentimental, apoyo familiar o ámbito laboral)

- adjetivos calificativos utilizados (belleza, polémica y escándalos o maternidad y cuidados)

- roles desempeñados (si son presentadas como WAGs, profesionales o mixto y cuál es más relevante dentro del contexto de la noticia).

\section{Resultados}

\subsection{Presencia por años}

El volumen de noticias sobre WAGs es similar en tres diarios (Marca, 27; As, 46 y Mundo deportivo, 50) mientras que Sport acumula 295. La evolución de estos contenidos es ascendente. Aunque aparecen noticias antes de 2013, es a partir de esta fecha cuando se produce un incremento en tres diarios. Resulta distinto el caso de Sport, que comenzó esta tendencia en 2011 y ha aumentado exponencialmente, aunque con cierto retroceso en 2015 (gráfico 1).

\subsection{Distribución de noticias por secciones}

Los contenidos sobre WAGs suelen localizarse en secciones de entretenimiento, galerías fotográficas o blogs específicos, debido a su escasa relevancia informativa dentro del entorno deportivo. Como muestra la tabla 1, Mundo deportivo incrementa las noticias sobre WAGs en secciones más relevantes como Fútbol (30\%), en As destaca la sección Ocio (48\%) y en Marca, Buzz.Marca (41\%). Sport ofrece claras diferencias, ya que casi el $100 \%$ se localizan en el blog Elbalonrosa.com, que también distribuye las noticias en sec-

ciones, lideradas por Galerías (53\%). Los espacios de mayor prestigio como Fútbol, Baloncesto o Motor están reservados a deportistas masculinos, mientras que las secciones de ocio, entretenimiento o humor están destinadas a mujeres no deportistas. Por tanto el diario que más presencia otorga a las WAGs en secciones de entretenimiento es Sport con el $100 \%$, seguido de Marca en torno al $90 \%$. Mundo deportivo es el medio que más noticias de este tipo sitúa en secciones de mayor relevancia informativa, un $36 \%$.

\subsection{Clasificación de noticias por deportes}

Aunque el concepto WAGs está referido a esposas y novias de deportistas en general, el deporte más representativo es el fútbol, con mayor número de noticias. En Sport alcanza el $90 \%$ de las informaciones y el $63 \%$ en Marca. Les siguen de lejos las noticias relativas al baloncesto y las que agrupan varios deportes, y resultan anecdóticas las informaciones sobre tenis, fórmula 1 o fútbol americano, que no superan el $3 \%$ en ningún medio. Se aprecia que estos diarios prestan especial atención a las noticias sobre las WAGs del fútbol por encima de otros deportes, de manera que la vinculación sentimental de estas mujeres con los futbolistas de élite hace que existan mayores opciones de aparecer en tales noticias que si la relación es mantenida con otro tipo de deportistas, especialmente en Sport. Esto hace que predominen los estereotipos hegemónicos de masculinidad y feminidad tradicionales (tabla 2).

\subsection{Tipo y extensión de las noticias}

Se han establecido unas categorías comunes para recoger el tipo de noticias existentes en los periódicos digitales sobre las WAGs. Estas informaciones pueden presentarse como

Tabla 1. Clasificación de noticias por sección

\begin{tabular}{|c|c|c|c|c|c|c|c|c|c|c|c|}
\hline \multicolumn{3}{|c|}{ Marca } & \multicolumn{3}{|c|}{ Mundo deportivo } & \multicolumn{3}{|c|}{ As } & \multicolumn{3}{|c|}{ Sport } \\
\hline Sección & $\mathbf{n}$ & $\%$ & Sección & $\mathbf{n}$ & $\%$ & Sección & $\mathbf{n}$ & $\%$ & Sección & $\mathbf{n}$ & $\%$ \\
\hline Buzz.Marca & 11 & 40,7 & Fútbol & 15 & 30,0 & Ocio & 22 & 47,8 & Noticias. Fuera de juego & 1 & 0,3 \\
\hline Blogs & 9 & 33,3 & Vaya mundo & 13 & 26,0 & As fotos & 9 & 19,6 & Elbalonrosa & 294 & 99,7 \\
\hline Fotogalerías & 5 & 18,5 & Otros & 12 & 24,0 & Vídeos & 9 & 19,6 & & & \\
\hline Baloncesto & 1 & 3,7 & Ocio & 7 & 14,0 & Más fútbol & 6 & 13,0 & & & \\
\hline Fútbol & 1 & 3,7 & Fútbol internacional & 3 & 6,0 & & & & & & \\
\hline
\end{tabular}


Tabla 2. Clasificación de noticias por deportes

\begin{tabular}{|l|c|c|c|c|c|c|c|c|}
\hline \multicolumn{1}{c|}{} & \multicolumn{2}{c|}{ Marca } & Mundo deportivo & \multicolumn{2}{c|}{ As } & \multicolumn{2}{c|}{ Sport } \\
\cline { 2 - 10 } & $\mathbf{n}$ & $\%$ & $\mathbf{n}$ & $\%$ & $\mathbf{n}$ & $\%$ & $\mathbf{n}$ & $\%$ \\
\hline Fútbol & 17 & 63,0 & 42 & 84,0 & 39 & 84,8 & 266 & 90,2 \\
\hline Baloncesto & 6 & 22,2 & 2 & 4,0 & 4 & 8,7 & 4 & 1,4 \\
\hline Fórmula 1 & 0 & 0,0 & 0 & 0,0 & 1 & 2,2 & 3 & 1,0 \\
\hline Tenis & 0 & 0,0 & 1 & 2,0 & 0 & 0,0 & 3 & 1,0 \\
\hline Golf & 0 & 0,0 & 1 & 2,0 & 0 & 0,0 & 0 & 0,0 \\
\hline Fútbol americano & 0 & 0,0 & 1 & 2,0 & 1 & 2,2 & 1 & 0,3 \\
\hline Beisbol & 1 & 3,7 & 0 & 0,0 & 0 & 0,0 & 3 & 1,0 \\
\hline Criquet & 1 & 3,7 & 0 & 0,0 & 0 & 0,0 & 0 & 0,0 \\
\hline Boxeo & 0 & 0,0 & 0 & 0,0 & 0 & 0,0 & 3 & 1,0 \\
\hline Varios & 2 & 7,4 & 3 & 6,0 & 1 & 2,2 & 12 & 4,1 \\
\hline & 27 & 100 & 50 & 100 & 46 & 100,0 & 295 & 100,0 \\
\hline
\end{tabular}

- noticias

- fotogalerías

- fotonoticias

- videonoticias

- encuestas (sólo en Sport).

Los contenidos presentados como noticias son elevados (82\% en Mundo deportivo, siendo el menor en Marca, $7 \%$ ) y en su mayoría aparecen junto a recursos visuales sobre estas mujeres como acompañantes, madres y apoyo al deportista, o de carácter erótico, semidesnudas y desnudas con actitudes de incitación sexual y accesibilidad. Las noticias que carecen de imágenes apenas llegan a una publicación en As, 2 en Marca y 3 en Mundo deportivo. Estos recursos visuales presentan mayoritariamente a las WAGs de forma cosificada y sexualizada, lo que perpetúa los estereotipos tradicionales, al servir como entretenimiento para el público masculino y disminuir los referentes femeninos profesionales.

Las fotonoticias, informaciones compuestas por una fotografía y un breve texto explicativo algo mayor que un pie de foto, son escasas ( $A s, 9 \%$ y Marca, $7 \%$ ). Esto se debe a que las informaciones suelen ser mucho más visuales, presentadas sobre todo como fotogalerías ( $81 \%$ en Marca o $37 \%$ en As). La presencia de videonoticias, formadas por un vídeo y un breve texto explicativo es mucho menor, siendo sólo representativa en As (20\%). Llama la atención que además de las noticias, no aparecen otros géneros periodísticos como reportajes o entrevistas, que aportarían información más completa y contextualizada sobre estas mujeres, en lugar de limitarse a recoger sus declaraciones parciales o más polémicas.

El caso de Sport ofrece particularidades. Sus contenidos se presentan principalmente como noticias (81\%), y las fotogalerías en sí mismas apenas representan el $1 \%$. Esto no se debe a una ausencia de imágenes, sino a que cada noticia está acompañada por una galería fotográfica propia para ilus- trar cada texto con imágenes. Este medio incluye encuestas mensuales y anuales como tipo de contenido en un $16 \%$ de las informaciones sobre WAGs, para que los usuarios elijan a la mujer más votada en ese período, y por tanto, su favorita en función de sus atributos físicos. En total se han encontrado 46 encuestas formadas cada una por un fotomontaje de 8 imágenes de las mujeres candidatas en actitudes sexualizadas. Es posible conocer la retroalimentación e impacto en los usuarios de tales contenidos mediante su nivel de respuesta. La media ponderada de votos recibidos por cada encuesta alcanza los 10.000 , cifra de impacto considerable teniendo en cuenta que se trata de un blog perteneciente a Sport y no del propio diario (gráfico 2).

En lo referente a la extensión dentro de la categoría noticias, se imponen las más breves, de alrededor de cincuenta palabras (As, 69\%; Sport, 59\% y Mundo deportivo, 44\%), le siguen las noticias de media página, que superan el $30 \%$ en Mundo deportivo y Sport y las de página completa, con el $100 \%$ en Marca, con sólo dos noticias, ya que la mayoría se presentan en otros tipos, le seguirían Mundo deportivo (24\%), As (13\%) y Sport (4\%). Este análisis aporta información sobre el tratamiento formal dado a estas noticias, en donde el interés no recae tanto en la extensión, que se presupone escasa debido al relativo valor informativo en lo deportivo, sino al tipo de noticias, al ser piezas especialmente visuales, sin interés por profundizar en la realidad de estas mujeres, sino en la mera transmisión de imágenes y valoraciones estereotipadas femeninas motivadas por el clic rápido del usuario, principalmente masculino.

\subsection{Autoría}

Los medios mantienen al hombre como sujeto y objeto mayoritario de las noticias en un $82 \%$ cuando se menciona el sexo, frente al $17 \%$ de menciones femeninas (Franquet;

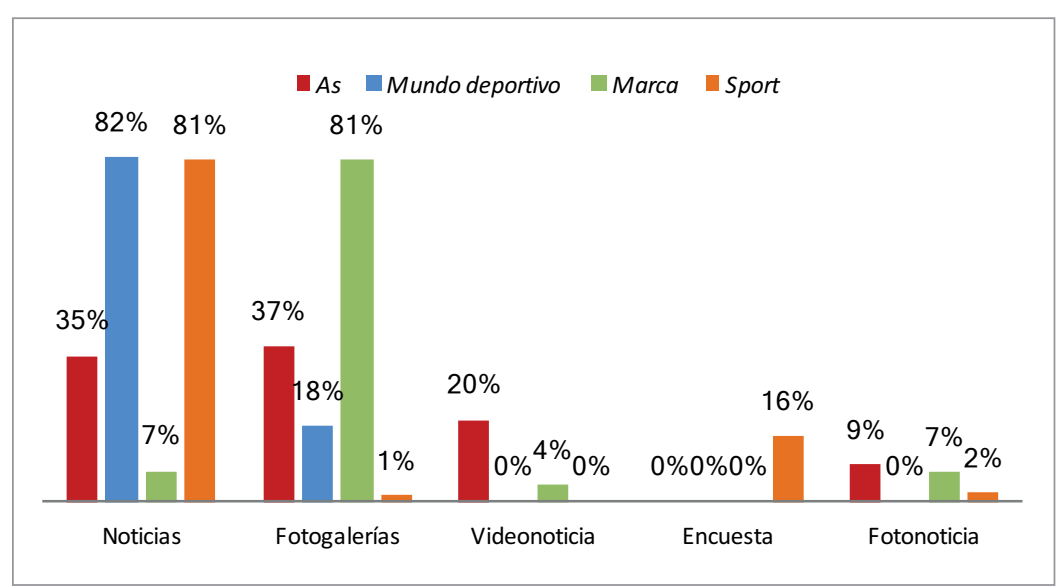

Gráfico 2. Tipo de noticias sobre WAGs 
Luzón; Ramajo, 2007). En este análisis se aprecia que los diarios digitales deportivos dejan la autoría poco clara, al omitirla o diluirla en la categoría Redacción. En su análisis, Tamarit; Quintana-Paz; Plaza (2011, pp. 247-260) ya afirmaban que

"la mayor parte de las noticias donde las mujeres son las protagonistas no están firmadas por ningún redactor".

En este estudio no se aprecia autoría en ninguna noticia de Sport, tampoco en el $63 \%$ de Marca, en el $22 \%$ de Mundo deportivo y en el $13 \%$ de As. En los casos en que se especifica, la autoría masculina sigue siendo mayor que la femenina en todos los diarios (37\% en Marca, 35\% en As y 6\% en Mundo deportivo). Frente a estas cifras, la presencia de mujeres como autoras es anecdótica, ni Sport ni Marca registra ningún caso, y en As y Mundo deportivo el porcentaje ronda el 2\%, habiéndose contabilizado una sola redactora en cada medio.

\section{En los titulares se suscita el interés del lector mediante vocablos llamativos con connotaciones sexuales o de doble sen- tido}

\subsection{Titulares}

Los titulares son de suma importancia en la prensa porque su función es "atraer la atención al relato" (Van-Dijk, 1983, p. 86). Ofrecen el rasgo más notorio de un discurso informativo: "aportan una definición (subjetiva) de la situación" (Van-Dijk, 1997, p. 108). Los redactores de tales discursos poseen una intención consciente de conquistar al lector, utilizando para ello mecanismos informativos y lingüísticos para generar un gran impacto (Romero-Álvarez, 2010).

En los cuatro diarios existe esta necesidad de suscitar el interés del lector mediante vocablos llamativos con connotaciones sexuales o de doble sentido, exclamaciones e interrogaciones que se despejan al abrir la noticia o listas. Entre los recursos lingüísticos más utilizados en el titular destaca la abundante presencia de palabras relativas a atributos fisicos femeninos (términos como: sensual, sexy, musa o diosa) predominantes en Marca (62\%) y seguidos de As (41\%), Mundo deportivo (38\%) y Sport (24\%), aunque cuantitativamente este último posee más titulares llamativos, un total de 72 , al registrar mayor volumen de noticias.

También son abundantes los titulares que presentan listas (Marca 37\%, Mundo deportivo 28\%, Sport 25\% y As 21\%), destacando ejemplos habituales como "Las WAGs más imponentes de la Premier League" y otros que buscan mayor complicidad con el lector: "8 WAGs vestidas para repartir alegría esta navidad" o "10 WAGs por las que deberías empezar a ver más partidos de la Premier League". En este último caso el titular apela directamente al lector, al utilizar el verbo en segunda persona del singular y una llamada a la acción. Encontramos por tanto que Marca es el diario que más abusa de los titulares sensacionalistas a través de recursos expresivos y ranking de belleza sobre las WAGs, siendo Sport el que menos emplea tales recursos.
Se ha revisado la designación de estas mujeres en los titulares: en todos ellos lo más habitual es no incluir sus nombres, o ser nombradas por términos como: WAGS, "novia de", "esposa de", "chicas" e incluso "amiguita de". Expresado en porcentajes, Marca es el que menos las nominaliza (78\%), seguido de Mundo deportivo (72\%), Sport (53\%) y As (34\%). En segundo lugar aparecen referidas con nombres y apellidos completos principalmente en As (34\%) y Sport (22\%) frente a Mundo deportivo y Marca (14\% cada uno) mientras que la designación por nombre sin apellidos es utilizada en Sport (21\%) y As (15\%). También se han contabilizado como "otros" aquellas formas de designación que responden a nombres artísticos, diminutivos o apellidos del esposo tales como "la señora Ribery", destacando aquí As y Mundo deportivo con los mayores porcentajes (15\% y $14 \%$ respectivamente). Si se suman los porcentajes en los que no aparece nombre y apellido o aparecen otras formas de designación, encontramos que en los titulares de estos diarios las mujeres son nombradas mayoritariamente (Mundo deportivo, 86\%; Marca, 85\%; Sport, 77\%; As, 65\%) de forma despersonalizada, mediante atributos físicos y de manera indirecta por derivación de sus parejas.

\subsection{Tema principal de las noticias sobre WAGs}

Se han establecido cuatro categorías (gráfico 3):

- relación sentimental;

- acompañante y apoyo familiar;

- vida social y belleza;

- ámbito profesional.

Se pueden dar de forma simultánea en una noticia, pero se ha primado la de mayor peso. La primera categoría recoge los contenidos sobre relaciones sentimentales entre WAGs y deportistas, y tiene mayor porcentaje en Mundo deportivo (18\%). La siguiente categoría integra las noticias relativas al papel de acompañantes y madres (apoyo familiar y cuidadoras) y cuenta con especial importancia en As (35\%). Las alusiones a familia, bodas o maternidad son constantes en la mayoría de las noticias, aunque no constituyan el tema principal, y por ello, no se reflejen en tales porcentajes. EI protagonismo que estos diarios atribuyen al papel de acompañantes como elemento estabilizador de los deportistas es muy importante, de modo que se ha encontrado una noticia en Marca y otra en Sport donde la ausencia de WAGs es suplida con la presencia de una MILF (acrónimo de mother I'd like to fuck y referido a las madres de los deportistas, consideradas mayores, pero sexualmente atractivas). Por otro lado, la presencia de estas mujeres en ocasiones es percibida como una amenaza para la estabilidad de los deportistas (Vaczi, 2014). Destacan titulares como "Capello permitirá a las esposas de los jugadores ir al Mundial", tras una noticia sobre su prohibición o "las mujeres y los niños invaden el Camp Nou", donde el verbo transmite al lector la idea de amenaza ocasionada por una irrupción o entrada por la fuerza.

La tercera categoría concentra mayores porcentajes en todos los diarios (Marca, $77 \%$ y el menor As, $39 \%$ ) y su tema central es vida social, ocio y belleza. Tales noticias tienen como principal finalidad presentar a los lectores los nuevos 
"fichajes femeninos" de los equipos de fútbol. Establecen comparativas sobre cómo sería el equipo ideal si estuviese formado por mujeres, utilizando un lenguaje de rivalidad e incluso bélico para referirse a ellas, con ejemplos como "la envidia de la Premier", "estalla la guerra de WAGs", "ataque frontal", "duelo de bellezas", o "sexy guerra de almohadas", lo que perpetúa roles estereotipados femeninos basados en la envidia, los celos y la vanidad. También se han encontrado noticias que utilizan metáforas entre estas mujeres y objetos o situaciones deportivas, lo que supone su cosificación: "Vajna, el mejor penalti de Luka Modrik", "El equipazo del Dormund también goleó en Estambul" o "espectacular tridente de WAGs colchoneras". Además son comparadas continuamente entre ellas, aumentando la rivalidad y competitividad basadas en su belleza física: "Carol Cabrino, la Shakira del central Marquinhos", "Elena, la Bardot italiana" o "lista para suplir a Sara Carbonero". Cuando estas mujeres no se ajustan al modelo de feminidad establecido, se utilizan términos despectivos contra ellas tales como "Victoria Beckham: la reina de las WAGs ya es una cuarentona", en el que se aprecia que el medio, en este caso Sport.es, encuentra esta edad superior a lo esperado para este perfil.

Por último resultan habituales en todos los diarios comentarios relativos a aspectos sexuales que intentan suscitar la complicidad con el lector, como "Las chicas calientan la Premier League", "Katherine Webb: iestá para comérsela!", "Nives sube la temperatura", entre otros.

La categoría relativa al ámbito profesional cuenta con unas cifras anecdóticas, al no tener presencia en Marca y un $2 \%$ en Mundo deportivo, aunque en Sport y As se aprecia cierto aumento, con un $5 \%$ y $11 \%$ respectivamente. En la mayoría de estas noticias los logros profesionales quedan solapados a los de sus parejas, al ser comparados entre sí o atribuir su éxito profesional a su relación sentimental y no a sus capacidades, especialmente en profesiones vinculadas a la moda e imagen. Estos diarios prestan especial atención a las mujeres que aparcan su vida profesional para acompañar a sus parejas y servirles de apoyo en sus nuevos equipos, y sancionan a aquellas que no se identifican con el rol de acompañantes. A pesar de la poca cobertura ofrecida a la carrera profesional de las esposas y novias, sí hay cabida para informar sobre sus fracasos profesionales, utilizándose expresiones como "se estrella", "es gafe" o "sus proyectos televisivos han fracasado".

Se han extraído del total de noticias, aquellas referidas a hechos negativos y polémicos, como infidelidades, peleas o escándalos. El diario Sport es el que incluye mayor porcentaje publica (31\%) y por tanto el que mayor número de noticias sensacionalistas, seguido de Marca (28\%). Estos diarios suelen alabar a aquellas mujeres que, aunque tengan protagonismo por su belleza y sensualidad, mantienen un perfil bajo en las redes sociales con actitud de discreción, apoyo a sus parejas y cuidado de los hijos. El tratamiento es sancionador en las que tienen mayor presencia pública o son acusadas de infidelidad, con apelativos como "amiguita" o "cazafutbolistas". Se han encontrado noticias que intentan suscitar el interés con hechos morbosos como enfermedades: "Dos WAGs acercan la gripe porcina a la Premier", frivolizando con asesinatos: "Nabilla: la WAG asesina volvió a casa por Navidad", atribuyendo a éstas los malos resultados de los deportistas: "la maldición mundialista de las WAGs campeonas", o como víctimas: "Las WAGs, víctimas del 'mercato'".

\subsection{Asignación de roles}

Las mujeres suelen aparecer reflejadas en los medios de masas desempeñando roles tradicionales, principalmente en espacios privados y domésticos, frente al rol del varón, asociado a la esfera pública (Mateos-de-Cabo, 2007). Se han establecido tres categorías:
- esposas y novias profesionales;
- esposas y novias no profesionales;
- combinación de ambas pero con preponderancia del rol de acompañante.

Es necesario señalar que la pertinencia de publicar estas noticias está en los cuatro diarios vinculada a las relaciones sentimentales entre deportistas y WAGs, de manera que todas las noticias analizadas presentan a las mujeres con el rol principal de novias, esposas, parejas o ex parejas de alguien, mientras que el varón destaca por su profesionalidad y logro deportivo. Dicho lo cual, al rol femenino se añaden en distinto grado en cada diario contadas referencias a sus carreras profesionales.

Mundo deportivo y Marca ofrecen una imagen basada principalmente en el rol de esposas y novias (70\%), sin reconocerles logros profesionales. Se han encontrado noticias que incluyen aspectos profesionales de estas mujeres, aunque como rol secundario después del de novias y esposas, principalmente en Sport (53\%) y As (41\%). Esto no es debido a una presentación más equilibrada de éstas, pues en tales casos reciben la designación de "WAGs atípicas". La inmensa mayoría de las profesiones femeninas que se recogen en estos diarios son las de modelo, actriz, cantante y presentadora, y en muchos casos, esta información se incluye para justificar la presencia de imágenes eróticas de estas. Aunque se han encontrado algunas noticias que definían a sus protagonistas como profesionales en algún campo, en la mayoría se asociaban posteriormente a un varón para ser

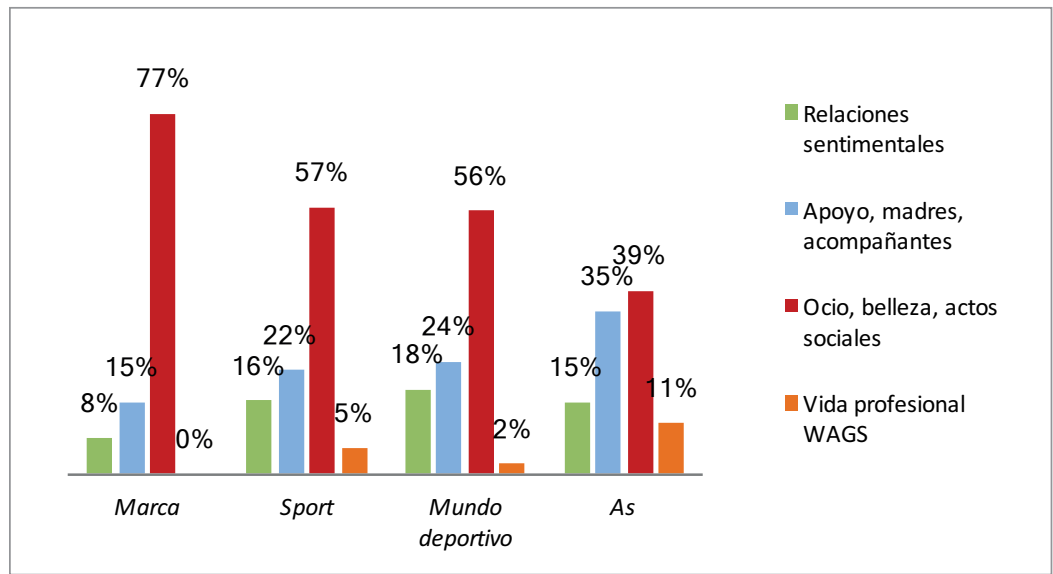

Gráfico 3. Tema principal de las noticias sobre WAGs 
nombradas, por lo que las noticias contabilizadas con el rol profesional como preponderante sólo aparecen en As (2\%). Observando las cifras se aprecia que Mundo deportivo y Marca son los diarios que más roles de género transmiten a sus respectivas audiencias, siendo Sport el que más recoge otras facetas de estas mujeres.

Los cuatro diarios presentan a mujeres con un elevado nivel de dependencia del varón, esto se muestra en el tratamiento de las informaciones sobre cambios de equipo de los deportistas y por tanto, de ciudad o país. Se aprecia una tendencia favorable a que las WAGs acompañen a sus parejas en sus nuevos destinos, sacrificando sus propias carreras profesionales. En cambio, para el deportista la pareja es pres-

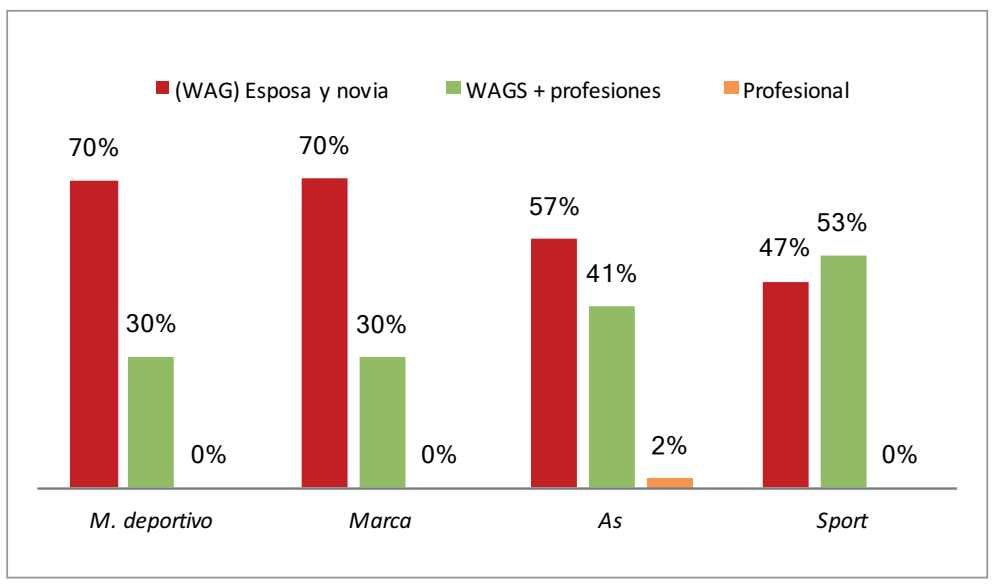

Gráfico 4. Roles desempeñados por las WAGs

cindible e intercambiable, con expresiones como "estrena novia", "nueva conquista" o "inmejorable sustituta". Queda evidenciado que estos diarios perpetúan los roles tradicionales de género, impidiendo un desarrollo social y profesional igualitario (gráfico 4).

\section{Discusión y conclusiones}

Tras analizar las noticias sobre WAGs en los cuatro diarios digitales de mayor número de lectores, se puede sostener que en todos ellos existe un desigual tratamiento entre mujeres y hombres (Franquet; Luzón; Ramajo, 2007; Rojas-Torrijos, 2010; Sainz-de-Baranda-Andújar, 2014b) no sólo cuantitativo sino también cualitativo. Las WAGs son definidas por su vida sentimental y esfera privada, presentándolas con patrones de feminidad tradicional basados en la belleza y apoyo al varón (Morris, 1981; Gmelch; San-Antonio, 2001; Clayton; Harris, 2004) y como mujeres fatales (Forsyth; Thompson, 2007; Vaczi, 2014), mientras que los deportistas representan un ideal de masculinidad hegemónica (Trujillo, 1991; Messner; Cooky, 2010), mediante el reconocimiento de sus logros deportivos y adjetivos que alaban su profesionalidad.

\section{En los cuatro diarios analizados existe un desigual tratamiento entre mujeres y hombres no sólo cuantitativo sino tam- bién cualitativo}

Entre 2013 y 2015 se han incrementado las noticias sobre WAGs en los cuatro periódicos digitales deportivos, especialmente en Sport, con 295 noticias y un blog destinado específicamente a estas informaciones.

Estas noticias suelen relegarse a secciones poco relevantes, como ocio y entretenimiento y vinculadas al fútbol (80\% en tres de los diarios). Al no otorgarles valor deportivo, disminuye su carácter informativo desplazándose a la opinión y valoración de sus autores, que evalúan el aspecto físico de estas mujeres.

Su formato y extensión principales son las noticias breves (50\% en tres de los diarios) con fotografías o galerías fotográficas de estas mujeres en actitudes de disponibilidad e incitación sexual, especialmente en Sport, donde todas las informaciones repiten este patrón.
Su autoría es principalmente desconocida o recae en manos masculinas, frente a las mujeres que aparecen como redactoras en el $2 \%$ de las informaciones.

Entre el $25-60 \%$ de los titulares utilizan recursos expresivos para atraer a los lectores, como interrogaciones, rankings de belleza y adjetivos calificativos sobre estas mujeres. Son designadas mayoritariamente en los titulares de forma impersonal (entre un $65-85 \%$ en todos los diarios) mediante vocablos sobre su belleza y sexualidad como "diosa", "explosiva WAG" o por derivación del varón, "esposa de", en lugar de utilizar sus nombres y apellidos.

\section{Las mujeres son cosificadas mediante imágenes, adjetivos, comparaciones en- tre ellas y metáforas con el deporte}

El tema principal y roles utilizados ahondan en los tradicionales estereotipos femeninos de belleza, maternidad y apoyo al varón, reduciéndose notablemente su faceta profesional, y en los casos en que sí se reconoce, está asociada al fracaso o al éxito alcanzado gracias a su aspecto físico o relación sentimental. Las mujeres son cosificadas mediante imágenes, adjetivos, comparaciones entre ellas y metáforas con el deporte.

Las noticias polémicas alcanzan el $20-30 \%$ del total y refuerzan los estereotipos negativos de conflictividad, menor capacidad de controlar las emociones y vinculación de las mujeres a la naturaleza, frente a la cultura atribuida al varón. Se incluyen noticias de hechos negativos que ensalzan el morbo, como asesinatos, enfermedades o victimizarlas.

La principal finalidad es ofrecer a los lectores noticias de entretenimiento con alto contenido visual, donde se muestran mujeres en actitudes sensuales y sin valor informativo. En el diario Sport esto es reforzado con encuestas (16\%), cuyo objetivo es clasificar a las mujeres por sus atributos físicos.

Teniendo en cuenta los datos expuestos, se puede afirmar que las noticias sobre WAGs imponen unos modelos de referencia para los lectores de los diarios digitales deportivos basados en la cosificación, dependencia y subordinación de éstas. Además se ha encontrado un tratamiento despersonalizado, banal y estereotipado de estas mujeres, especial- 
mente en Marca y Mundo deportivo. El aumento de estas noticias, repercute en la percepción que sus lectores tienen sobre ellas, que encuentran numerosos referentes femeninos destinados a trasmitir como valores a seguir la belleza, maternidad y apoyo al éxito profesional del varón en detrimento del propio.

\section{Se ha encontrado un tratamiento des- personalizado, banal y estereotipado de estas mujeres, especialmente en Marca y Mundo deportivo}

\section{Referencias}

AIMC (2015). Resumen general EGM febrero a noviembre 2015. http://www.aimc.es/a1mc-c0nt3nt/uploads/2015/12/ resumegm315.pdf

Allen, Kim; Mendick, Heather (2013). "Young people's uses of celebrity: Class, gender and improper celebrity". Discourse: Studies in the cultural politics of education, v. $34, \mathrm{n}$. 1, pp. 77-93.

https://goo.gl/1kDkeM

https://doi.org/10.1080/01596306.2012.698865

Ayala-Castro, María-Concepción; Fernández-Soriano, Emelina; Fernández-de-la-Torre, María-Dolores (2001). Jornadas de comunicación y género. Málaga: Centro de ediciones de la Diputación de Málaga. ISBN: 9788477854289

Bardin, Laurence (2002). Análisis de contenido. Madrid: Akal. ISBN: 8476000936

Bishop, Ronald (2003). "Missing in action: Feature coverage of women's sports in Sports illustrated". Journal of sport \& social issues, v. 27, n. 2, pp. 184-194.

https://www.researchgate.net/publication/249675926_ Missing_In_Action

https://doi.org/10.1177/0193732502250718

Bullen, Jennifer (2014). Media representations of footballers' wives: A wag's life. New York: Palgrave Macmillan. ISBN: 9781137335685

Burstyn, Varda (1999). The rites of men: Manhood, politics, and the culture of sport. Toronto: University of Toronto Press. ISBN: 0802077250

Caudwell, Jayne; Browne, Kath (2011). "Sexy spaces: Geography and leisure intersectionalities". Leisure studies, v. 30, n. 2, pp. 117-122.

https://doi.org/10.1080/02614367.2011.561977

Clayton, Ben; Harris, John (2004). “Footballers' wives: The role of the soccer player's partner in the construction of idealized masculinity". Soccer \& society, v. 5 n. 3, pp. 317-335. https://doi.org/10.1080/1466097042000279580

Clayton, Ben; Humberstone, Barbara (2006). “Men's talk a (pro)feminist analysis of male university football players' discourse". International review for the sociology of sport, v. 41, n. 3-4, pp. 295-316.

https://goo.gl/m4MX5N

https://doi.org/10.1177/1012690207078380
Connell, Raewyn (1987). Gender and power: Society, the person, and sexual politics. Cambridge: Polity Press. ISBN: 9780745665276

Coy, Maddy (2009). "Milkshakes, lady lumps and growing up to want boobies: How the sexualisation of popular culture limits girl's horizons". Child abuse review, v. 18, n. 6, pp. 372-383.

https://goo.gl/hP3jrT

https://doi.org/10.1002/car.1094

Duncan, Margaret-Carlisle; Messner, Michael; Williams, Linda (1991). Coverage of women's sports in four daily newspapers. Los Angeles: The Amateur Athletic Foundation of Los Angeles.

https://goo.gl/rWkZQX

Fink, Janet; Kensicki, Linda-Jean (2002). “An imperceptible difference: Visual and textual constructions of femininity in Sports illustrated and Sports illustrated for women". Mass communication and society, v. 5, n. 3, pp. 317-339.

https://ir.canterbury.ac.nz/handle/10092/636

http://dx.doi.org/10.1207/S15327825MCS0503_5

Forsyth, Craig; Thompson, Carol (2007). "Helpmates of the rodeo: Fans, wives, and groupies". Journal of sport \& social issues, v. 31, n. 4, pp. 394-416.

https://goo.gl/hEG3MD

https://doi.org/10.1177/0193723507307812

Franquet, Rosa; Luzón, Virginia; Ramajo, Natividad (2006). "Mujer y medios de comunicación on-line. Un análisis de género". En: Sabés-Turmo, Fernando. Análisis y propuestas en torno al periodismo digital: VII Congreso nacional periodismo digital, 2-3 de marzo, pp. 94-108. Huesca: Asociación de la Prensa de Aragón.

https://dialnet.unirioja.es/servlet/articulo?codigo $=4177536$

Franquet, Rosa; Luzón, Virginia; Ramajo, Natividad (2007). "La información en los principales medios de comunicación on-line. Estudiar la representación de género". Zer: Revista de estudios de comunicación = Komunikazio ikasketen aldizkaria, v. 12, n. 22, pp. 267-282.

http://www.ehu.eus/ojs/index.php/Zer/article/view/3688

Frideres, Jilian-Elizabeth; Palao-Andrés, José-Manuel (2006). "Análisis de las noticias deportivas de dos periódicos digitales de España y Estados Unidos: ¿promoción de la actividad física y el deporte?". Apunts. Educación física y deportes, v. 3, n. 85, pp. 7-14.

http://www.raco.cat/index.php/ApuntsEFD/article/ view/300845

García-Altadill, Elisabet; De-Moragas, Miquel; Gómez-Benosa, Miguel (1994). "El deporte en las televisiones españolas: un papel creciente en la programación". Telos: cuadernos de comunicación, tecnología y sociedad, n. 38, pp. 109-118. https://ddd.uab.cat/pub/artpub/1994/106419/telos_ a1994n38p109.pdf

García-Meseguer, Álvaro (2002). “El español, una lengua no sexista". Estudios de lingüística del español, v. 16. http://goo.gl/pCwcq

Gmelch, George; San-Antonio, Patricia-Mary (2001). "Baseball wives: Gender and the work of baseball". Journal of 
contemporary ethnography, v. 30, n. 3, pp. 335-356.

https://goo.gl/S2P5rM

https://doi.org/10.1177/089124101030003003

Harditya, Dwinda (2013). "WAGs (wives and girlfriends) figures in tabloid soccer (semiotical analysis of soccer babes column and love story column in tabloid soccer)". Semerag: Universitas Diponegoro, pp. 1-14.

https://goo.gl/Q8FUCE

Hargreaves, Jennifer (1994). Sporting females: Critical issues in the history and sociology of women's sports. London: Routledge. ISBN: 0415070287

Harris, John (2005). "The image problem in women's football". Journal of sport \& social issues, v. 29, n. 2, pp. 184-197. https://goo.gl/WuVgG6 https://doi.org/10.1177/0193723504273120

Koivula, Nathalie (1999). "Gender stereotyping in televised media sport coverage". Sex roles, v. 41, n. 7-8, pp. 589-604. https://goo.gl/JviqxQ https://doi.org/10.1023/A:1018899522353

Krippendorff, Klaus (1990). Metodología de análisis de contenido. Teoría y práctica. Barcelona: Paidós. ISBN: 847509 6271

Lippmann, Walter (2003). La opinión pública. Madrid: Langre. ISBN: 9788493238131

Martínez-Oña, María-del-Mar; Muñoz-Muñoz, Ana M. (2015). "Iconografía, estereotipos y manipulación fotográfica de la belleza femenina". Estudios sobre el mensaje periodístico, v. 21, n. 1, pp. 369-384.

https://doi.org/10.5209/rev_ESMP.2015.v21.n1.49100

Mateos-de-Cabo, Ruth (coord.) (2007). La presencia de estereotipos en los medios de comunicación: análisis de la prensa digital española. Madrid: Dirección General de la Mujer, Comunidad de Madrid.

http://goo.gl/rxuiQW

Messner, Michael; Cooky, Cheryl (2010). Gender in televised sport: News and highlights shows, 1989-2009. Los Angeles: Center for Feminist Research, University of Southern California.

http://dornsifecms.usc.edu/assets/sites/80/docs/tvsports.pdf

Morris, Desmond (1981). The soccer tribe. London: Jonathan Cape Co. ISBN: 9780586059289

Pearson, Judy; Turner, Lynn; Mancillas, W. Todd (1993). Comunicación y género. Barcelona: Paidós. ISBN: 97884 75099248

Rojas-Torrijos, José-Luis (2010). "La construcción de las noticias deportivas desde una mirada androcéntrica. De la invisibilidad a los estereotipos de la mujer deportista". Vivat academia, n. 113, pp. 122-136.

https://doi.org/10.15178/va.2010.113.122-136

Romero-Álvarez, María-de-Lourdes (2010). "Las figuras retóricas en los titulares periodísticos de la ciudad de México". En: Actas del XVI Congreso de la Asociación Internacional de Hispanistas: Nuevos caminos del hispanismo, pp. 1-8. https://goo.gl/pMmQLY
Roth, Amanda; Basow, Susan (2004). "Femininity, sports, and feminism: Developing a theory of physical liberation". Journal of sport \& social issues, v. 28, n. 3, pp. 245-265. https://goo.gl/jwwpjf https://doi.org/10.1177/0193723504266990

Rubin, Margot (2009). “The offside rule: Women's bodies in masculinised spaces". En: Pillay, Udesh; Tomlinson, Richard; Bass, Orli. Development and dreams: The urban legacy of the 2010 football world cup, pp. 266-280. Cape Town: HSRC Press. ISBN: 9780796922502

https://goo.gl/5y8yNS

Rubinstein, Gidi; Lansisky, Lior (2013). "Beauty and the best: Authoritarianism and gender roles of Israeli footballers, basketballers, non-athletes, and their wives". Personality and individual differences, v. 55, n. 4, pp. 411- 416. https://goo.gl/5GYWZF https://doi.org/10.1016/j.paid.2013.03.015

Sainz-de-Baranda-Andújar, Clara (2013). Mujeres y deporte en los medios de comunicación. Estudio de la prensa deportiva española (1978-2010). Tesis doctoral, Universidad Carlos III de Madrid.

https://e-archivo.uc3m.es/handle/10016/16505

Sainz-de-Baranda-Andújar, Clara (2014a). "Las mujeres en la prensa deportiva: dos perfiles". Cuadernos de psicología del deporte, v. 14, n. 1, pp. 91-102.

http://goo.gl/cOqnOh

Sainz-De-Baranda-Andújar, Clara (2014b). “El género de los protagonistas en la información deportiva (1979-2010): noticias y titulares". Estudios sobre el mensaje periodístico, v. 20, n. 2, pp. $1225-1236$.

https://doi.org/10.5209/rev_ESMP.2014.v20.n2.47062

Scolari, Carlos (2008). Hipermediaciones. Elementos para una teoría de la comunicación digital interactiva. Barcelona: Editorial Gedisa. ISBN: 9788497842730

Tamarit, Ana; Quintana-Paz, Nuria; Plaza, Juan (2011). "¿Quién habla de las mujeres en las noticias donde ellas son las protagonistas?". Palabra clave, v. 14, n. 2, pp. 247-260. http://www.scielo.org.co/pdf/pacla/v14n2/v14n2a05

Trujillo, Nick (1991). "Hegemonic masculinity on the mound: Media representations of Nolan Ryan and American sport culture". Critical studies in mass communication, v. 8, n. 3, pp. 290-308. https://goo.gl/2MiMjJ https://doi.org/10.1080/15295039109366799

Vaczi, Mariann (2014). "Dangerous liaisons, fatal women: The fear and fantasy of soccer wives and girlfriends in Spain". International review for the sociology of sport, v. 51, n. 3, pp. 299-313.

https://goo.gl/VNDdis

https://doi.org/10.1177/1012690214524756

Van-Dijk, Teun A. (1983). "Estructuras textuales de las noticias de prensa". Análisi. Quaderns de comunicació i cultura, n. 7-8, pp. 77-105.

http://goo.gl/RoN2Qf

Van-Dijk, Teun A. (1997). Racismo y análisis crítico de los medios. Barcelona: Paidós. ISBN: 9788449303678 